\title{
Modeling the Effects of Interactions between Environmental Variables on the State of an Environmental Issue: The Case of the Morelos State in Mexico
}

\author{
Fernando Ramos-Quintana1*, Deny L. Hernández-Rabadán², Enrique Sánchez-Salinas', \\ María Laura Ortiz-Hernández ${ }^{1}$, María Luisa Castrejón-Godínez ${ }^{1}$, Edgar Dantán-González ${ }^{1}$ \\ ${ }^{1}$ Biotechnology Research Center, Autonomous University of the Morelos State, Cuernavaca, México \\ ${ }^{2}$ Graduate Program in Computer Science, Instituto Tecnológico y de Estudios Superiores de Monterrey (ITESM), \\ Xochitepec, México \\ Email: ${ }^{*}$ ramosfernando747@gmail.com
}

Received 2 March 2015; accepted 16 March 2015; published 19 March 2015

Copyright (C) 2015 by authors and Scientific Research Publishing Inc.

This work is licensed under the Creative Commons Attribution International License (CC BY). http://creativecommons.org/licenses/by/4.0/ c) (i) Open Access

\section{Abstract}

An important use of environmental indicators is oriented to know their individual impact on the whole environment quality. Nevertheless, most of the important causes of environment affectations are derived from multiple interactions between indicators which correspond more specifically to the environmental reality. The affectations derived from interactions should be analyzed and interpreted through numerical expressions representing a relevant challenge for developers of environmental indicators. To cope with the analysis and interpretation problem, we propose in this work a methodology in two senses: in a bottom-up sense a directed graph is built representing interactions between environmental indicators as behavioral relations, which exert an effect on the state of an environmental issue of a site over time (10 years); in a top-down sense to assist users in the analysis and interpretation of interactions through a computer interface that provides users with the capacity of knowing how and what relational behaviors between indicators are affecting, the most or the least, the performance of the environmental issue being studied. This methodology was applied to the analysis an interpretation of interactions between environmental variables that affect the state of an environmental quality issue related with the State of Morelos in Mexico. The results showed the adequate expressivity of a directed graph to represent interactions allowed to verify the coherence of the numerical values associated with their behaviors during a period of time and with their effects on the environmental issue under study.

\footnotetext{
*Corresponding author.
}

How to cite this paper: Ramos-Quintana, F., Hernández-Rabadán, D.L., Sánchez-Salinas, E., Ortiz-Hernández, M.L., CastrejónGodínez, M.L. and Dantán-González, E. (2015) Modeling the Effects of Interactions between Environmental Variables on the State of an Environmental Issue: The Case of the Morelos State in Mexico. Journal of Environmental Protection, 6, 225236. http://dx.doi.org/10.4236/jep.2015.63023 


\section{Keywords}

\section{Environmental Indicators, Graphs, Interactions}

\section{Introduction}

A significant milestone in the development of environmental indicators was the Declaration of Rio de Janeiro on Environment and Development (ONU, 1992), which established that: "Indicators of sustainable development need to be developed to provide, solid bases for decision-making at all levels and contribute to a self-regulating sustainability of integrated environment and development systems" [1]; in the same decade the development of the PSR (Pressure-State-Response) framework contributed to facilitate the interpretation of indicators [2]-[4]; other efforts, from several institutions were made to contribute to the development of environmental indicators [5]; some derivations of such framework extended the PSR model to introduce the concept of Driving ForceState-Response framework [6]-[8]. An extension of this framework was the DPSIR (Driving Force-PressureState-Impact-Response) framework, which was created by introducing the concept of "Impact" [9] [10]. Applications of the DPSIR framework are presented in [11] [12]. Another framework is proposed through the development of key indexes, such as: Pollution index, Wasted Resources Index; an index related with the Risk of Ecosystems; and the index of Environmental Impact on Human Welfare [13]; in the 2012-European meeting about the environment, it started the discussion about green economy. For instance, in the European Environmental Indicator Report (2012) is strongly discussed that the Green Economy should be supported by the relation of two relevant issues: the use of resources in an efficient way by taking care of the ecosystems robustness [14]. In the EEA's European environment-state and outlook 2010, it was analyzed and identified the transition to a "green economy" as a key priority in the years ahead. A green economy was defined as "one in which environmental, economic and social policies and innovations enable society to use resources efficiently, thereby enhancing human well-being in an inclusive manner, while maintaining the natural systems that sustain us” [15].

Environmental reports from different international organisms have been promoters and providers of guidelines for initiatives related with models of environmental indicators/indices, whose main purposes is to establish trends towards the green economy for a sustainable development of countries based on the use of environmental indicators [16]-[20].

In most of the initiatives and the experience discussed above, it is highlighted that the way of transmitting the environmental information is crucial to tackle the problematic related with the environmental damage and the climatic change on the human welfare. Such is the case of the recent document from the OCDE [21], where it is pointed out that policies that promote Green Growth need to be founded on a good understanding of the determinants of green growth and of related trade-offs or synergies. The information of results obtained and the progress to be made should be appropriate, which requires indicators capable of sending clear messages to policy makers and to the general public. In addition, the indicators should be defined within conceptual frameworks and based on internationally comparable data.

On the one side, environmental information can be useful to decision makers to establish public policies aiming at regulating the dynamic of the environmental damage derived from the involved multiple factors. On the other side, for the general public the quality of the transmitted information is relevant towards the motivation and education of the environmental awareness by respecting rules related with the use of natural resources. As a matter of fact, one of the aspects that place the Scandinavia region at the top of the most advanced countries working on programs for the environment defense is precisely their high level of environmental culture and education.

Usually, environmental data are expressed quantitatively through environmental indicators (for instance, $\mathrm{CO}_{2}$ emissions, PM particles, etc.) using tables or graphics that shows the indicator behavior over time. An adequate representation of environmental information can help non-governmental organizations, such as EPHA Environment Network [22] to support their initiative in defense of the environment as means to improving the health and well-being of European citizens with arguments based on data indicators, easily interpretable.

The interpretation of environmental data should be supported by representations able to express the behavior of indicators in the environment affectations. These affectations are produced by simple or multiple relations 
between indicators, the latter corresponding more precisely to aggregated indicators, which can be distributed under diverse structures, such as trees, causal chains or causal networks, among others [2] [10]. Such relations could be expressed as dependencies. For instance, Rousval [23] affirms that almost $50 \%$ of $\mathrm{CO}_{2}$ emissions come from transport effects, whose growth of number of vehicles is quite related with the population growth. Meanwhile, Joumard considers that representation of effects is needed for an accurate and transparent environmental sustainability assessment. He argues that for the description and representation of environmental impacts the use of causal chains between a source and a final target is a correct approach [24]. These two examples show the high level dependency relationship between variables, which affects the state of an environmental issue.

Information of environmental indicators represented by numerical values could result too much abstract to express and interpret how the behaviors due to interactions between indicators impact on the performance of an environmental issue, which could result in a more valuable information for users; Ralston [25] argues that if there were no index regarding environmental health that could be used to objectively guide scientific opinion, scientists could not properly inform decision makers and the public about the need of responding in order to avert or ameliorate risks; Meanwhile Ebert [26] highlights the importance of aggregated variables by considering that environmental indices provide a condensed description of multi-dimensional environmental states by aggregating several variables (or indicators) into a single quantity; we use environmental indices to mean an aggregate of environmental indicators, which generally implies conversion to common units and application of weights (i.e., averaging, adding, or application of other mathematical operators). Aggregated indicators or indices specify an architecture that identifies high priority issues with all metrics calculated on a common scale [27].

Based on the importance of the environmental information to be transmitted to users, as discussed before, designers and developers are obligated to search for relevant aspects to be developed. Taking into account the multi-factorial nature, we aimed at analyzing environmental issues by dealing with the following relevant aspects: 1) to build expressive representations capable of being easily interpretable; 2) to consider interactions between indicators expressed as behavioral relations when the state of environmental issue is to be analyzed; 3) to provide users with a computer interface to assist them in the analysis and interpretation of environmental information. These three aspects will facilitate the task of interpretation of data for the purposes of decision makers, as well as the task of understanding the environmental problematic by the general public.

The work presented in this paper aims at coping with these relevant aspects by proposing a methodology in two senses: 1) in a bottom-up sense we build directed graphs from data representing indicators and relations between them. Through the aid of directed graph, users can verify the coherence of environmental relations; 2) in a top-down sense, a computer interface will allow users to track the different relations represented in the graph and analyze the behaviors of relations between indicators that can affect more significantly the state of the environmental issue under study. We will show the case of the environmental quality issue under construction, which is based on real data of the Morelos State, in Mexico. The main variables interacting in this issue are the following: $\mathrm{CO}_{2}$, Transport, Population, Water availability and Waste Material. This work, currently in progress, is planned towards the construction of a more complete study of an environmental quality issue by aggregating more environmental variables to the graph.

\section{Methodology}

As mentioned before, our methodology is composed of two main senses: the construction of the graph representing the interactions between environmental variables is based on a bottom-up mode; for the analysis of the graph users can track it in a top-down sense evaluating the graphics related with the interactions between environmental variables.

\subsection{The Construction of the Directed Graph: A Bottom-Up Sense}

The following section aims at showing the method to build the graph of relations and the set of operations to determine values that indicate numerically how behaviors of relations affect the state of the environmental issue under study.

The environmental issue to be studied is represented by a graph that is formally expressed as:

$$
G=\{N, L\}
$$

where: 
$N$ represents the set of nodes, which in turn represent environmental variables;

$L$ represents the set of arcs or links that relate two nodes (environmental variables).

The arcs that link the nodes are represented by arrows which entail a semantic meaning in the relation. Thereby, in the graph are represented links that should satisfy coherently environmental relations. We use the data of individual indicators and then we build the relevant relations that contribute to the construction of the graph in a coherent way.

Figure 1 shows a bottom-up model to build the graph representing the environmental issue to be analyzed. The primary data of indicators, which should be validated, are situated at the bottom of the pyramid. At the second layer of the pyramid the individual indicators are built. At the third layer the relations between indicators are built. At the fourth layer, the top of the pyramid, the graph represents the environmental quality issue under study.

We start by defining a set of elementary or basic relations (interactions) that can be found within a graph of relations. These basic relations can be combined to form more complex relations until obtaining a graph that can represent the environmental issue to be studied. Thereby, the basic relations represent building blocks to build more complex relations.

We have to recall that we are looking for measuring how interactions between indicators affect the environmental issue under study. Thus, the interactions between indicators are represented by behaviors of relations, where both variables that compose the relations have as common variable a period of time of 10 years.

We illustrate through an example how it works. Figure 2(a) and Figure 2(b) show two graphics of indicators ( $V 1$ and $V 2$ ) versus time. Meanwhile, Figure 2(c) illustrates the relation of $V 1$ with $V 2$.

As mentioned before, we are interested in knowing the behavior of the influence of the relations between indicators in the state of environmental issue under study. As we can see, the relation between $V 1$ and V2 (Figure $2(c))$ is represented by the curve in red color. However, for practical purposes, this curve is approximated by a

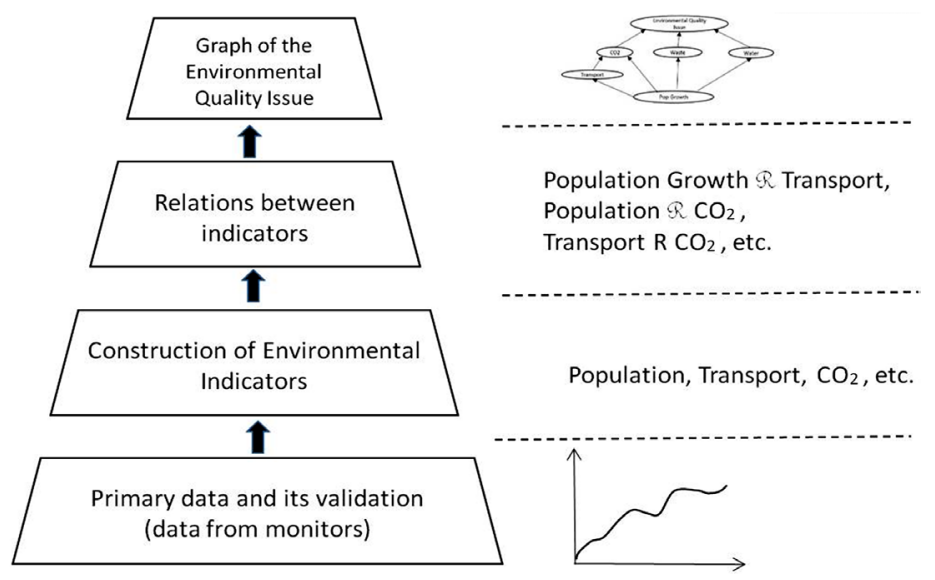

Figure 1. This pyramid shows the different layers to build the graph that represents the environmental issue under study. We highlight that this way of doing facilitates the construction of interactions related with a representation of an environmental issue (bottom-up sense). The analysis is carried-out through a top-down sense.

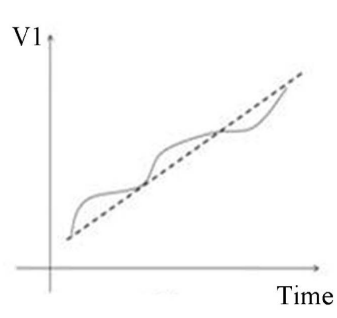

(a)

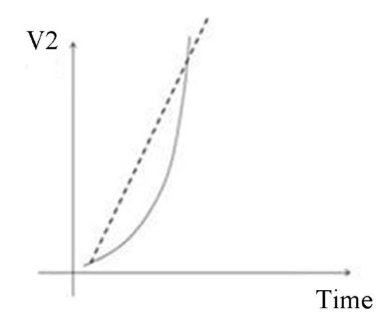

(b)

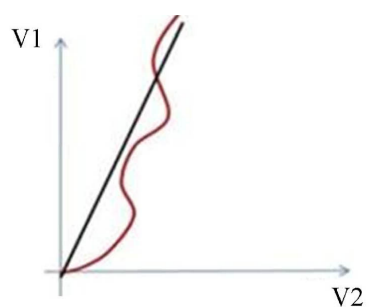

(c)

Figure 2. (a) and (b) show the graphics of $V 1$ and $V 2$ versus time, respectively. (c) $V 1$ versus $V 2$, having the time as common variable. 
slope in black color. The slope will serve to indicate behaviors based on downward or upward tendencies. A similar idea is applied for the case of the variable $V 1$ and $V 2$ in Figure 2(a) and Figure 2(b). That is, the curve represents the real behavior and the overlapped slope an approximation. This result shows that the value of $V 1$ increases more significantly, as the time increases, than the value of $V 2$. It means that $V 2$ exerts an important influence in $V 1$, that is, this relation affects importantly the state of the environmental issue, which is the focus of the analysis.

Thereby, we could define a set of rules that can provide us with information about the behavior of both variables and compare each other to know their influence in the environmental issue under analysis. For the definition of these rules the angle formed by the axes $V 1$ and $V 2$ has been used, as shown by Equation (2):

$$
\alpha=\operatorname{tg}^{-1}\left(\frac{V 1}{V 2}\right)
$$

The angle $\alpha$ could vary from $0^{\circ}$ to $90^{\circ}$. Based on the value of angles, we have defined three regions that involve a semantic meaning about the behaviors of the relations under study, as follows:

\section{Rule for the Region 1}

- if $\operatorname{tg}(\alpha)$ tends to the value of 0 , then the angle $\alpha$ tends to $0^{\circ}$.

It means that the value of the abscissa (x-axis) increases more significantly than the value of the ordinate (yaxis). In terms of influence, the relation between variables brings about a poor influence in the state of the environmental issue under study, wherein no matter the increment of the abscissa the increment of the ordinate is not significant.

\section{Rule for the Region 2}

- if $\operatorname{tg}(\alpha)$ tends to the value of 1 , then the angle $\alpha$ tends to $45^{\circ}$.

It means that the value of the angle is situated in the neighborhood of $45^{\circ}$, or the value of the tangent is close to 1 , wherein in this case, both variables are changing in a similar proportion. In terms of influence, both variables are influencing in a similar proportion in the environmental issue under study.

\section{Rule for the Region 3}

- if $\operatorname{tg}(\alpha)$ tends to values much bigger than 1 , then the angle $\alpha$ tends to $90^{\circ}$.

It means that the ordinate (y-axis) value increases more significantly than the increment of the abscissa (xaxis), or a little variation of the abscissa entails a very big variation of the ordinate. In terms of influence, the relation between these variables brings about a very, very considerable influence in the state of the environmental issue being studied.

Based on the definitions of regions described above, we assume that the values of relations will be in the range from "0" to theoretically " $\infty$ " (infinite), but in practical terms we will consider "very big values" instead of "infinite values".

\section{The Graph Representing the Environmental Issue Study: Basic Definitions}

We show in this section an example of the graph treated in this work. Before dealing with this example, a set of definitions should be established to facilitate the understanding of the relations of the graph and how they are combined to through operations to express a value that shows the influence or effect of relations on the state of the environmental issue being analyzed.

- Basic relation 1: graphically the most basic relation is represented in Figure 3(a). It can be read as: "indicator $\boldsymbol{a}$ is related with indicator $\boldsymbol{b}$ ". This relation can be expressed as: $\boldsymbol{a} \boldsymbol{R} \boldsymbol{b}$, where $\boldsymbol{R}$ represent a particular relation between $\boldsymbol{a}$ and $\boldsymbol{b}$. For the sake of expressivity, we will use more frequently the symbol " $\rightarrow$ " instead of " $\boldsymbol{R}$ " as follows: (a $\rightarrow$ b) to mean that variable "a" influence or has an effect on variable "b".

- Basic relation 2: the basic relation based on a transitivity rule is represented in Figure 3(b). In this situation there are two relations that are linked based on a transitivity rule, as follows: "If $\boldsymbol{a}$ is related with $\boldsymbol{b}$ and $\boldsymbol{b}$ is related with $\boldsymbol{c}$, then $\boldsymbol{a}$ is related with $\boldsymbol{c}$ through $\boldsymbol{b}$ by transitivity”. This situation is expressed by equation 3:

$$
\text { if }(a R b) \otimes(b R c), \quad \text { then }(a R c)_{b}
$$

The precedent situation can be found frequently in real situations, for instance, "if the population growth is related with the transportation growth \& if the transportation growth is related with the $\mathrm{CO}_{2}$ growth, then the population growth is related with the $\mathrm{CO}_{2}$ growth by transitivity through transportation”. 


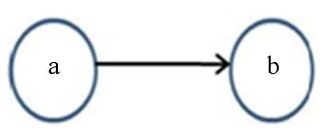

(a)

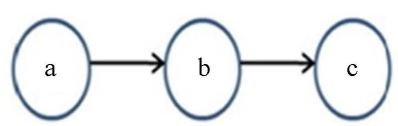

(b)

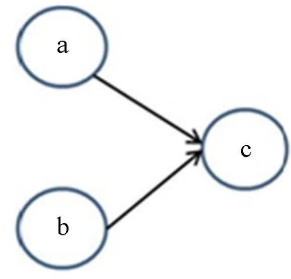

(c)

Figure 3. Basic relations.

- Basic relation 3: two or more relations point to the same node, this relation is shown in Figure 3(c). For instance, in this situation two nodes, $\boldsymbol{a}$ and $\boldsymbol{b}$, from different paths point to the target node $\boldsymbol{c}$. This relation needs the definition of an operator to express that the final result is the sum of two relations, which is quite different than the basic relation number 2 defined before. This operator is represented by $\oplus$, which expresses a sum of relations, in this case, it is expressed by equation 4 as follows:

$$
(a R c) \oplus(b R c)
$$

An example of the combination of precedent basic relations is illustrated by the graph shown in Figure 4. This complex relation represents the relation between Pop (population) and Trans (transport), and the relation between Transport and $\mathrm{CO}_{2}$. Thus, population is related directly with $\mathrm{CO}_{2}$ and indirectly through transport. We can express symbolically such a situation by Equation (5) as follows:

$$
(\text { Pop } R \text { Transp }) \otimes\left(\text { Transp } R \mathrm{CO}_{2}\right)=\left(\text { Pop } R \mathrm{CO}_{2}\right)_{\text {Transp }}
$$

This situation can happen in the reality, because, as we already know, the population growth contributes to the increment of $\mathbf{C O}_{2}$ production without passing, necessarily, through the transport. Thus in this case two paths point to the same node $\left(\mathbf{C O}_{2}\right.$, in this case). Thereby, the final representation is presented by Equation (6) as follows:

$$
\left((\text { Pop } R \text { Transp }) \otimes\left(\text { Transp } R \mathrm{CO}_{2}\right)\right) \oplus\left(\text { Pop } R \mathrm{CO}_{2}\right)
$$

The symbol " $\otimes$ " indicates that one relation is linked with a second one with a common node (that is, an indicator), which in this case is Transp. The symbol indicates also the multiplication of two expressions. Meanwhile symbol “ $\oplus$ ” indicates that two paths point to the same node, see basic relation 3 above, and the result is the sum of two relations. A more abbreviated form to express the same relation is by replacing the left expression by its equivalent expression shown above. Thus, the final abbreviated expression is represented by Equation (7):

$$
\left(\left(\text { Pop } R \mathrm{CO}_{2}\right)_{\text {Transp }}\right) \oplus\left(\operatorname{Pop} R \mathrm{CO}_{2}\right)
$$

It is important to point out that a formula, as the one shown above, should be able to be transformed into the graph from which the formula was obtained.

\subsection{The Graph Representing the Environmental Issue under Study Using Real Data}

The example of this work aims at measuring the influence of relations in an environmental issue that deals with important aspects of the quality of the environmental state. We use real data of the Morelos State in Mexico, from the year 2000 to 2010. Owing to the fact that this study is in progress, we show a part of the whole graph. Thus, our interest is just to show how the method works. However, the method is enough flexible and adaptable to add, delete or modify the topology of the graph as more indicators are incorporated to the graph. Table 1 shows the values of variables (during 10 years) involved in this study.

Figure 5 shows the graph of this example. We show how the increment of Population affects the increment of other indicators such as Transport, $\mathrm{CO}_{2}$, Waste and a decrement of Water Availability, which in turn, affects the quality of the environmental state. The target node is named "Environmental Quality Issue".

Using the rules described in the precedent section, we build the expression obtained from the graph illustrated in Figure 5. 


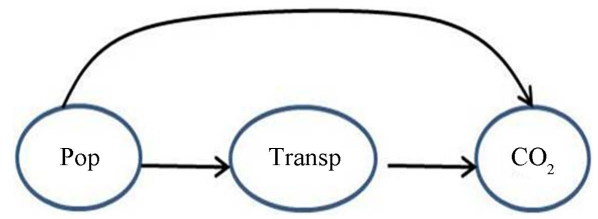

Figure 4. Graph with combination of basic relations.
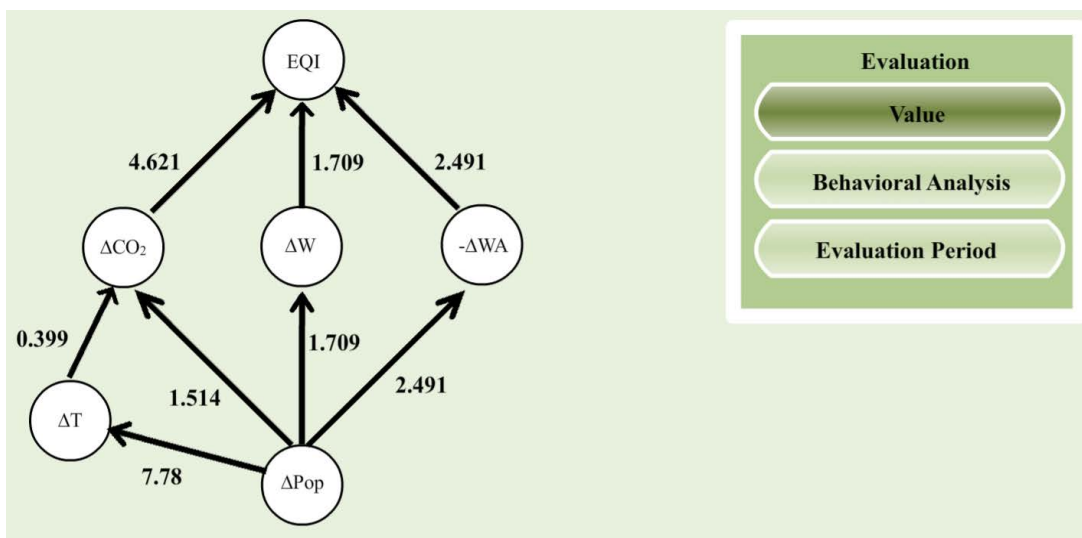

Figure 5. This figure shows the relations of five variables that influence the state of the “Environmental Quality” issue.

Table 1. Variable values to build the relations of the graph.

\begin{tabular}{cccccc}
\hline Time & Morelos Population & Transport & $\mathrm{CO}_{2}$ & Waste & Water Availability \\
\hline 2000 & $1,555,296$ & 155,600 & 4927.23 & 459 & - \\
2001 & $1,564,627$ & 175,000 & 5875.95 & 472 & 2818 \\
2002 & $1,574,015$ & 187,500 & 6175.26 & 483 & 2818 \\
2003 & $1,583,459$ & 192,500 & 6549.62 & 493 & 2713 \\
2004 & $1,592,960$ & 200,000 & 6260.64 & 526 & 2703 \\
2005 & $1,612,899$ & 212,500 & 7546.31 & 538 & 2746 \\
2006 & 1,645157 & 250,000 & 7346.75 & 548 & 2029 \\
2007 & $1,678,060$ & 270,000 & 7709.12 & 551 & 2055 \\
2008 & $1,711,621$ & 290,000 & 7214.24 & 555 & 2049 \\
2009 & $1,745,854$ & 310,000 & 7148.38 & 558 & 2040 \\
2010 & $1,777,227$ & 340,000 & 7923.13 & 596 & 1987 \\
\hline
\end{tabular}

Firstly, we identify a set of relations as the type of basic relations number 1, which are shown by expression (8) below (as usually the symbol " $\Delta$ " stands for "increment"):

$$
\begin{aligned}
& (\Delta \text { Population } \rightarrow \Delta \text { Transport }) \\
& \left(\Delta \text { Population } \rightarrow \Delta \mathrm{CO}_{2}\right) \\
& \left(\Delta \text { Transport } \rightarrow \Delta \mathrm{CO}_{2}\right) \\
& (\Delta \text { Population } \rightarrow \Delta \text { Waste }) \\
& (\Delta \text { Population } \rightarrow-\Delta \text { Water_Availability })
\end{aligned}
$$

The subgraph composed of nodes $\Delta$ Population, $\Delta$ Transport, $\Delta \mathrm{CO}_{2}$ contains the three basic relations described 
above. We identify a basic relation number 2, which in this case is represented by Equation (9):

$$
(\Delta \text { Population } \rightarrow \Delta \text { Transport }) \otimes\left(\Delta \text { Transport } \rightarrow \Delta \mathrm{CO}_{2}\right)=\left(\Delta \text { Population } \rightarrow \Delta \mathrm{CO}_{2}\right)_{\Delta \text { Transp }}
$$

This relation means that the increment of Population is related with the increment of $\mathrm{CO}_{2}$ through the increment of Transport, by transitivity.

The numerical result of this subgraph is calculated by equation (10) as follows:

$$
(\Delta \text { Population } \rightarrow \Delta \text { Transport }) \otimes\left(\Delta \text { Transport } \rightarrow \Delta \mathrm{CO}_{2}\right)=7.78 \times 0.3994=3.1073
$$

The value of the slope for the relation Population with $\mathrm{CO}_{2}$ Equation (11) is:

$$
\left(\Delta \text { Population } \rightarrow \Delta \mathrm{CO}_{2}\right)=1.514
$$

As described by basic relation 3 (Section 2.1.1.), these relations are added, which yields: 4.6213. The angle corresponding to this slope value (4.6213) is: $77.79^{\circ}$. The value of this angle falls down within the region 3 , close to the zone of $90^{\circ}$. Based on this value, we can conclude that the influence of this sub-graph in the target node is quite important.

The slope values for the two other relations are described by Equation (12) below:

$$
\begin{aligned}
& (\Delta \text { Population } \rightarrow \Delta \text { Waste })=1.709 \\
& (\Delta \text { Population } \rightarrow-\Delta \text { Water_Availability })=2.4914
\end{aligned}
$$

The above relations are added to obtain a final value of influence or affectation; it is computed by Equation (13) as follows:

$$
\begin{gathered}
\left((\Delta \text { Population } \rightarrow \Delta \text { Transport }) \otimes\left(\Delta \text { Transport } \rightarrow \Delta \mathrm{CO}_{2}\right)\right) \oplus(\Delta \text { Population } \rightarrow \Delta \text { Waste }) \\
\oplus(\Delta \text { Population } \rightarrow-\Delta \text { Water_Availability })=4.6213+1.709+2.4914=8.9029,
\end{gathered}
$$

The angle corresponding to the slope value $=8.9029$ is: $83.53^{\circ}$. The value of this angle falls down within the region 3 , close to the value of $90^{\circ}$, which is considered a dangerous neighborhood (see Section 2.1. for the definition of rules of regions $1,2,3$ ).

Obviously, certain users, such as the decision makers, could be interested in knowing the cause of this value, by looking at detail what or which relations have influenced, the most or the least, the final result. The next section deals with a computer interface that is useful to analyze how the behaviors of individual indicators, or the relations between them, have participated in the determination of the final value. The whole graph can be tracked relation by relation or node by node by displaying the graphics corresponding to the relations of the graph and/or the variables of the nodes versus time (10 years).

\subsection{The Interactive Analysis of the Index: A Top-Down Sense}

The section deals with the part of the methodology concerning the analysis of the graph. The users are endowed with capacities to analyze graphically the behavior of relations (links) and individual components (nodes). In this case the user will perform a downstream search by starting at the target node. At this point, see Figure 6, the nodes that point to the target node is displayed at the computer screen. Thereby, the user can decide what subgraph wants to analyze downstream to verify the indicators that were linked to build it by following the rule of basic relations discussed in Section 2.1.1. Once a sub-graph has been chosen, the user can display the graphics associated with each relation and with each node, see Figure 7 for an example.

\section{Analysis of Results: The Case of the State of Morelos, Mexico}

The model based on interactions is allowed to distinguish variables that play an important role and the interactions between variables whose joint behaviors within a period of time could be crucial in the state behavior of an environmental issue. Such is the case of two nodes (variables) of the graph: the Population node that plays the role of a source exerting an influence in almost all of the variables belonging to the graph; and obviously, the role played by the receptor of the influences of behaviors due to other variables individually and/or by considering interactions between them. Such role is played by the environmental quality node, which is called in this work the target node. 

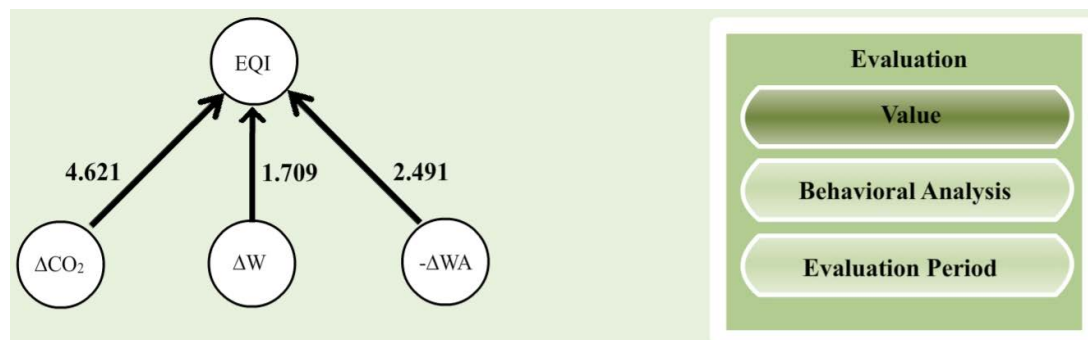

Figure 6. Set of nodes that point to the target node.

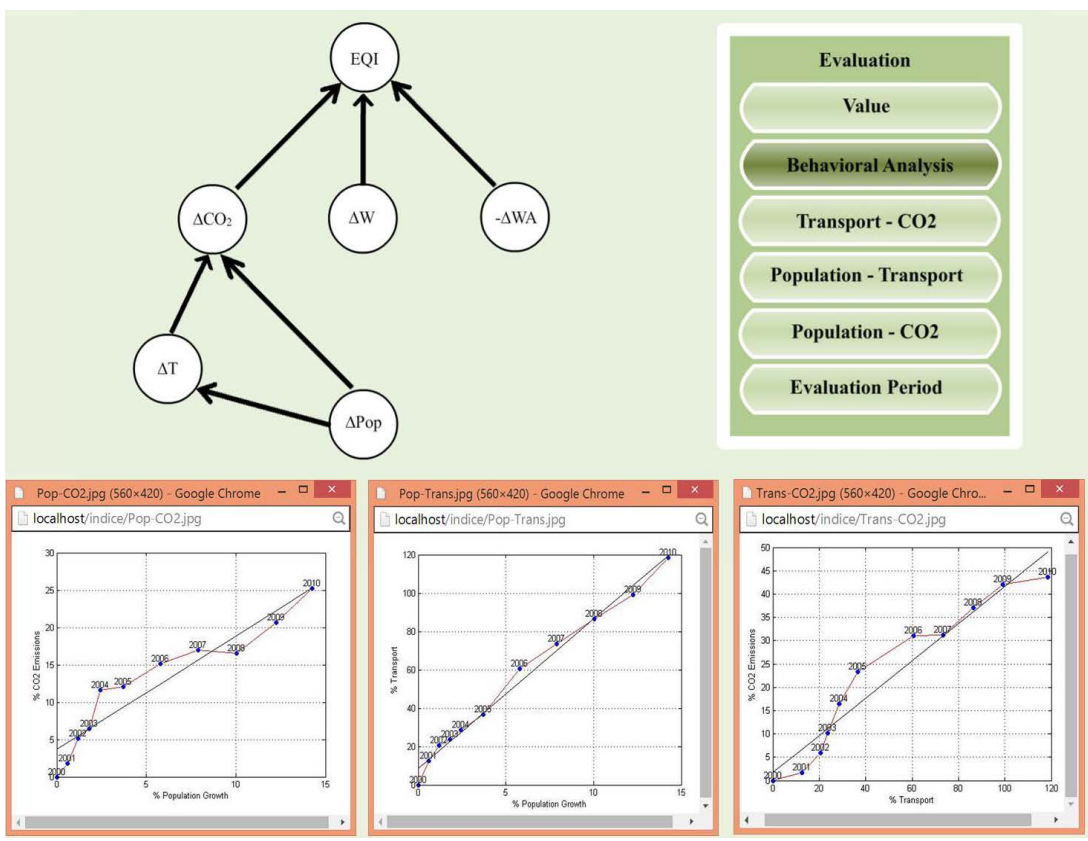

Figure 7. The subgraph that links Population with the target node, through $\mathrm{CO}_{2}$ and Transport, and the graphics corresponding to the relations involved in this subgraph are displayed.

Another advantage that is offered by the model based on interactions is because we are able to distinguish those relations that exert a particular influence or affect on the environmental issue being studied, through the values associated with each relation. In this example, we distinguish basically two types of relations that point to the target node: the relation that points directly from the source node (the Population node in this work) to the target node; and the relations that point from the source node to the target node through other variables by a transitivity rule, such is the case, for instance, of the Population node to the target node, through the Transport node to the $\mathrm{CO}_{2}$ node.

We discuss in particular the coherence of results yielded by the subgraph represented by the following operations in Equation (14):

$$
\begin{aligned}
(\Delta \text { Population } \rightarrow \Delta \text { Transport }) \otimes\left(\Delta \text { Transport } \rightarrow \Delta \mathrm{CO}_{2}\right)=\left(\Delta \text { Population } \rightarrow \Delta \mathrm{CO}_{2}\right)_{\Delta \text { Transp }} & =7.78 \times 0.3994 \\
& =3.1073,
\end{aligned}
$$

As we can see, two slope values are multiplied, where 7.78 represents a high value whose angle is $82.67^{\circ}$, which is considered as a value within the region 3 , meanwhile 0.3994 corresponds to an angle value of $21.77^{\circ}$, which is considered within the region 1 . It means a high value is combined with a low value yielding a final value of 3.1073 , whose corresponding angle value is $72.16^{\circ}$. This value is located within the region 3 , which is close to the neighborhood of the critical zone of $90^{\circ}$. The slope value of the relation between Population and $\mathrm{CO}_{2}$ is 1.514 , whose corresponding angle is $56.55^{\circ}$, that is, in the neighborhood of region 2 . The final slope val- 
ue for this subgraph is 4.6213 , whose corresponding angle value is $77.79^{\circ}$, that is, a high value still closer to the critical zone of $90^{\circ}$. This fact can be interpreted as the combination of the indirectly influence of population growth through the transportation growth to the $\mathrm{CO}_{2}$ growth with the direct influence of population growth to the $\mathrm{CO}_{2}$ growth increases the threat to the $\mathrm{CO}_{2}$ growth, as expected.

As mentioned before we are trying to express numerically the effects on the environmental quality issue due to interactions of several environmental variables, which are in this case: $\mathrm{CO}_{2}$ growth, the waste growth and the growth of the decrement of water availability over time. These three variables having as a common cause the population growth in the 10 years considered. This fact is reflected by the combination of these three environmental variables by the sum of slope values associated with each variable as shown in Figure 5 . Such sum was expressed by Equation (13). The angle corresponding to the slope value $=8.9029$ is: $83.53^{\circ}$, which is located within the region 3 . This value can be considered as serious threat to the state of the environmental quality issue due to the combination of three environmental variables that have an important role in the environmental quality.

For the case of the Morelos State being analyzed in this work, the population has grown considerably during the last decade due to immigration from other states and from Mexico City. A powerful reason is because Cuernavaca, the capital of the state which is very close to Mexico City, is an attractive place to live due to its very good weather during almost the 365 days of the year and the growth of the urban and industrial zones. These factors have brought about a serious increment of transport and industries that complicate the functioning of actions to maintain the equilibrium between the population growth and the growth of transport and industries without affecting considerably the growth in the generation of $\mathrm{CO}_{2}$. The results of the growth of waste and the decrement of water availability shown in the graph are also caused by the population growth over time. The behaviors shown by the relations of the graph can provide us with information to adopt preventing measures because the tendency for the three variables is towards a serious increment in the near future. This fact is also clearly reflected by the method presented in this work.

A number associated with an abstract concept, such as the environmental quality treated in this work, results always in a complicated task to be performed both for the analysis and the interpretation. The computer interface provide users with the facility of tracking the whole graph and knowing more precisely what values of relations are causing the most or the least effect on the environmental issue under study.

\section{Conclusions}

The analysis of the environmental state situated in a precise moment, for instance, a specific year, does not reveal relevant information because the variables involved in an environmental state are changing dynamically with the time. Instead, the behavior of an indicator during a period of time, for instance 10 years, can provide us with more useful information that allows to project behaviors into short, medium and long terms. Moreover, if behaviors due to interactions between indicators are available, the analysis becomes closer to the reality, because the problem of the environmental state is characterized by multiple interactions.

Nevertheless, the construction of such models becomes significantly harder to be achieved. The method that we proposed aimed at quantifying the effects of interactions between indicators on the state of an environmental issue. The interactions were expressed by behaviors of relations between pairs of variables during a period of time, instead of doing it in a precise moment. Such relations were put together in directed graph, were links represented the relations and nodes the environmental variables. This way of doing could provide us with information to project behaviors of relations between environmental indicators into short, medium and long terms. In addition, the fact of representing the interactions in a unique graph could highlight the most relevant variables and relations that influence the most, or the least, in the behavior of the state of the environmental issue under study. This fact results in an important aspect in the analysis and interpretation of the behaviors associated with the relations of the graph.

The operations associated with behaviors between related environmental variables reflected, in coherent way, the result of the interactions shown in the graph. As shown in this paper, if the behaviors of interactions are situated within one of the three regions considered, we will be able to know whether an interaction behavior is representing a high, medium or low risk to the environmental issue under study.

The interactive method to analyze the graph facilitates this interpretation, because we can go downstream until getting concrete information about indicators which can reveal a precise cause of a given value.

This work showed an advance of the development of an environmental issue related with the quality of the 
environmental state of the State of Morelos in Mexico. We need to add more indicators, which are under development, to complete the study. However, we aimed at showing how the methodology and the involved methods work in the construction of the graph and the interactive analysis to facilitate its interpretation. The method used for that purpose is enough flexible and adaptable to facilitate modifications and the update of the graph that represents the study of environmental issue.

\section{Acknowledgements}

We would like to express our acknowledgements to CONACYT-FOMIX of the Mexican Government of the State of Morelos, Mexico, for the financial support under the project No. 189949.

\section{References}

[1] Assembly, U.G. (1992) Rio Declaration on Environment and Development. Agenda, 21, 366-368. http://dx.doi.org/10.1017/s037689290003157x

[2] OECD (2003) Environmental Indicators. Development, Measurement and Use. Reference Paper, OECD, Paris.

[3] OECD (1993) OECD Core Set of Indicators for Environmental Performance Reviews: A Synthesis Report by the Group on the State of the Environment. Environment Monograph, Organization for the Economic Co-Operation and Development, Paris.

[4] OECD (1994) Environmental Indicators: OECD Core Set, Paris.

[5] Tunstall, D., Hammond, A. and Henninger, N. (1994) Developing Environmental Indicators. World Resources Institute, Washington DC.

[6] OECD (1998) Towards Sustainable Development: Environmental Indicators. Organization for Economic Cooperation and Development, Paris.

[7] Smeets, E. and Weterings, R. (1999) Environmental Indicators: Typology and Overview. Report No. 25, European Environment Agency, Copenhagen.

[8] OECD (2001) OECD Environmental Indicators: Towards Sustainable Development. Organization for Economic Cooperation and Development, Paris.

[9] Niemeijer, D. and de Groot, R.S. (2008) A Conceptual Framework for Selecting Environmental Indicator Sets. Ecological Indicators, 8, 14-25. http://dx.doi.org/10.1016/j.ecolind.2006.11.012

[10] Niemeijer, D. and de Groot, R. (2008) Framing Environmental Indicators: Moving from Causal Chains to Causal Networks. Environment, Development and Sustainability, 10, 89-106. http://dx.doi.org/10.1007/s10668-006-9040-9

[11] Rasi Nezami, S., Nazariha, M., Moridi, A. and Baghvand, A. (2013) Environmentally Sound Water Resources Management in Catchment Level Using DPSIR Model and Scenario Analysis. International Journal of Environmental Research, 7, 569-580.

[12] Shao, C., Guan, Y., Chu, C., Shi, R., Ju, M. and Shi, J. (2014) Trends Analysis of Ecological Environment Security Based on DPSIR Model in the Coastal Zone: A Survey Study in Tianjin, China. International Journal of Environmental Research, 8, 765-778.

[13] Hammond, A., Adriaanse, A., Rodenburg, E., Bryant, D. and Woodward, R. (1995) Environmental Indicators: A Systematic Approach to Measuring and Reporting on Environmental Policy Performance in the Context of Sustainable Development. World Resources Institute, Washington DC, 50.

[14] Martin, J., Henrichs, T., Francis, C., Hoogeveen, Y., Kazmierczyk, P., Pignatelli, R. and Seemore, C.F. (2012) Environmental Indicator Report 2012: Ecosystem Resilience and Resource Efficiency in a Green Economy in Europe. European Environmental Agency, Copenhagen.

[15] Hoogeveen, Y., Asquith, M., Jarosinska, D. and Henrichs, T. (2013) Environmental Indicator Report 2013. Natural Resources and Human Well-Being in a Green Economy. European Environment Agency, Copenhagen.

[16] Agenzia Europea dell'ambiente (2001) Environmental Signals 2001: European Environment Agency Regular Indicator Report. Office for Official Publications of the European Communities (IS); European Environment Agency (IS), Ufficio delle pubblicazioni ufficiali delle Comunità europee; Agenzia europea dell'ambiente.

[17] USEPA (2003) Draft Report on the Environment 2003. Report EPA 260-R-02-006. Washington DC.

[18] Esty, D.C., Levy, M., Srebotnjak, T. and de Sherbinin, A. (2005) Environmental Sustainability Index: Benchmarking National Environmental Stewardship. Yale Center for Environmental Law and Policy, New Haven, 47-60.

[19] UNEP (2002) Global Environment Outlook 3. United Nations Environment Programme, Nairobi.

[20] World Resources Institute (2005) World Resources 2005: The Wealth of the Poor: Managing Ecosystems to Fight Po- 
verty. Washington DC.

[21] OECD (2014) The OECD Green Growth Measurement Framework and Indicators. Green Growth Indicators, OECD Publishing, Paris. http://dx.doi.org/10.1787/9789264223202-en

[22] World Health Organization, Regional Office for Europe (2000) Environmental Health Indicators: Development of Methodology for the WHO European Region. Interim Report. http://www.euro.who.int/_data/assets/pdf_file/0009/120231/E71437.pdf

[23] Rousval, B. (2005). Aide Multicritère a L'evaluation de L’impact des Trasnports Sur L'environment. These de Doctorat, Université de Paris Pauphine, Paris.

[24] Joumard, R. (2011) Environmental Sustainability Assessments: Towards a New Framework. International Journal of Sustainable Society, 3, 133-150. http://dx.doi.org/10.1504/IJSSOC.2011.039918

[25] Ralston, N. (2011) Environmental Indicators with a Global View. Journal of Environmental Indicators, 6, 41-44.

[26] Ebert, U. and Welsch, H. (2004) Meaningful Environmental Indices: A Social Choice Approach. Journal of Environmental Economics and Management, 47, 270-283. http://dx.doi.org/10.1016/j.jeem.2003.09.001

[27] De Sherbinin, A., Reuben, A., Levy, M.A. and Johnson, L. (2013) Indicators in Practice: How Environmental Indicators Are Being Used in Policy and Management Contexts. Center for International Earth Science Information Network, New York; Yale Centre for Environment Law \& Policy, New Haven. 